\title{
Testing a Model of IR Radiative Losses
}

Conference Paper NREL/CP-3B0-46411

August 2009

\section{Preprint}

Frank Vignola

University of Oregon

Charles N. Long

Pacific Northwest National Laboratory

Ibrahim Reda

National Renewable Energy Laboratory

Presented at Society of Photo-Optical Instrumentation Engineers (SPIE) 2009 Conference

San Diego, California

August 2-6, 2009

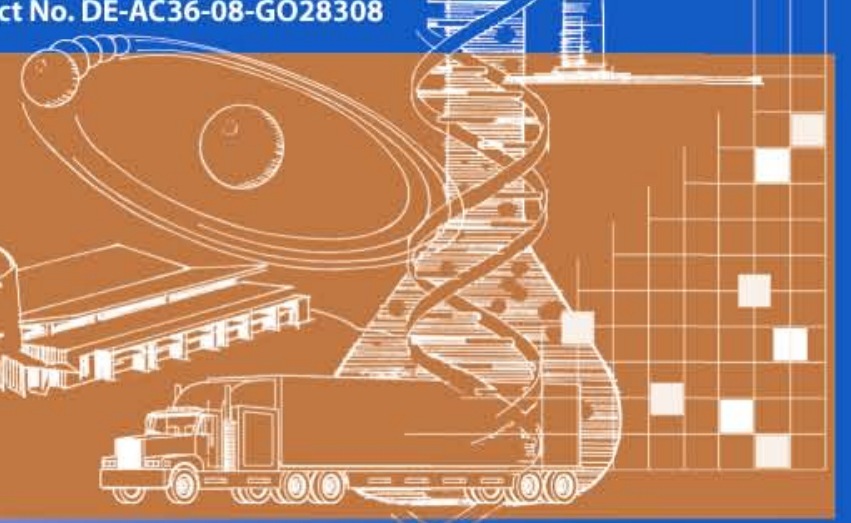




\section{NOTICE}

The submitted manuscript has been offered by an employee of the Alliance for Sustainable Energy, LLC (ASE), a contractor of the US Government under Contract No. DE-AC36-08-GO28308. Accordingly, the US Government and ASE retain a nonexclusive royalty-free license to publish or reproduce the published form of this contribution, or allow others to do so, for US Government purposes.

This report was prepared as an account of work sponsored by an agency of the United States government. Neither the United States government nor any agency thereof, nor any of their employees, makes any warranty, express or implied, or assumes any legal liability or responsibility for the accuracy, completeness, or usefulness of any information, apparatus, product, or process disclosed, or represents that its use would not infringe privately owned rights. Reference herein to any specific commercial product, process, or service by trade name, trademark, manufacturer, or otherwise does not necessarily constitute or imply its endorsement, recommendation, or favoring by the United States government or any agency thereof. The views and opinions of authors expressed herein do not necessarily state or reflect those of the United States government or any agency thereof.

Available electronically at http://www.osti.gov/bridge

Available for a processing fee to U.S. Department of Energy and its contractors, in paper, from:

U.S. Department of Energy

Office of Scientific and Technical Information

P.O. Box 62

Oak Ridge, TN 37831-0062

phone: 865.576 .8401

fax: 865.576 .5728

email: mailto:reports@adonis.osti.gov

Available for sale to the public, in paper, from:

U.S. Department of Commerce

National Technical Information Service

5285 Port Royal Road

Springfield, VA 22161

phone: 800.553.6847

fax: 703.605.6900

email: orders@ntis.fedworld.gov

online ordering: http://www.ntis.gov/ordering.htm 


\title{
Testing a model of IR radiative losses
}

\author{
Frank Vignola \\ University of Oregon \\ Department of Physics \\ Eugene, OR 97403 \\ Charles N. Long \\ Pacific Northwest National Laboratory \\ Ibrahim Reda \\ National Renewable Energy Laboratory
}

\begin{abstract}
Thermopile pyranometers exhibit IR radiative losses that affect global and diffuse shortwave measurements made with first class thermopile based instruments. Pyrgeometers can be used to measure the sky temperature and are used to calculate the pyranometer's IR radiative losses. Few solar monitoring sites are equipped with pyrgeometers necessary to account for the IR radiative losses associated with the pyranometers. High quality data from the Solar Radiation Research Laboratory (SRRL) at the National Renewable Energy Laboratory are used to test and further develop a model for the IR radiative losses without the use of pyrgeometer data. The various methods for obtaining IR radiative loss values are compared and contrasted using the SRRL data. A simple scaling method is proposed and tested to adjust the non-pyrgeometer based correlation models to sites with different sky temperature characteristics.
\end{abstract}

Keywords: Pyranometer, pyrgeometer, irradiance, IR, modeling, global, PSP

\section{INTRODUCTION}

Thermopile pyranometers exhibit IR radiative losses that affect global and diffuse shortwave measurements. Pyrgeometers are used to measure the downward long wavelength radiation (sky temperature) and hence can be used to estimate the pyranometer IR radiative losses ${ }^{1,2}$. The IR radiative losses reduce the measured short wavelength irradiance and create a systematic error in the measurements. Adjusting the pyranometer measurements for this IR radiative loss creates more precise global and diffuse values that are very useful for a wide variety of objectives from studying climate characteristics to estimating the performance of photovoltaic systems. Systematic errors affect correlation models as the systematic errors get integrated into the correlation results. Diffuse measurements are especially affected as the IR radiative losses can be ten percent or more of the diffuse values on clear days. Unfortunately the majority of sites that measure global and diffuse irradiance values do not have co-located pygeometer instruments. Therefore to remove the systematic errors from the sites without pyrgeometer data, it is necessary to develop a different method independent of the pyrgeometer measurements to correct for the systematic affect of IR radiative losses.

In previous papers, ${ }^{3,4}$ a prototype model based solely on measured meteorological and short wavelength irradiance data was created to approximate the IR radiative losses for Eugene, Oregon. While the IR loss correction model can be used to estimate the IR radiative losses for Eppley PSP pyranometers in Eugene, this "Eugene" correlation model was not expected to work well in areas with completely different sky temperature characteristics. An examination of the IR 
radiative losses in Golden, Colorado, confirms this assumption, and it was necessary to develop a method to adjust the Eugene IR radiative loss model to the conditions in Golden, Colorado. While comparing the Eugene correlation model with IR radiative measurement and other models, it was deemed useful to create an improved correlation-based model. Existing IR radiative loss models based on pyrgeometer measurements are also examined.

In this article, the IR radiative losses are studied for atmospheric conditions experienced in Golden, Colorado. The National Renewable Energy Laboratory (NREL) operates a very high quality solar monitoring station at the Solar Radiation Research Laboratory (SRRL). Besides the pyrgeometer based models and the Eugene correlation model, the data from SRRL ${ }^{5}$ are used to develop an alternate non-pyrgeometer correlation model for the IR radiative losses at SRRL. All the IR radiative loss models are compared and contrasted. Sky temperatures in Golden are typically much colder than those in Eugene, and the Golden IR radiative losses are approximately three times larger than those values measured in Eugene. Just how well the model derived in Eugene works in Golden is examined and a methodology is developed to adjust the Eugene model to the Golden, CO climate.

This article is organized as follows. The irradiance data from the Solar Radiation Research Laboratory at the National Renewable Energy Laboratory are briefly discussed. Next IR radiative loss models using pyrgeometer data are described. These models will be used in comparison with the Eugene and the Golden correlation-based IR radiative loss models. The method to adjust the Eugene model is then described. All the IR radiative loss models are then compared and contrasted. A summary of the work is presented along with suggestions for future directions.

\section{THE SRRL DATA}

NREL runs a very high quality solar radiation and meteorological monitoring station at SRRL in Golden, Colorado. SRRL is the home of the largest collection of radiometers in continuous operation, and its 75 instruments contribute the surface meteorological measurements to the Baseline Measurement System. All data collected by SRRL since 1981 are available to the public. The instruments are maintained on a daily basis, and calibration and maintenance records help ensure the quality of the data. A wide variety of solar monitoring instruments are utilized along with a comprehensive set of meteorological measurements. The one-minute data from this site can be downloaded from the SRRL website 5 .

The data used for this study are the raw global data from an Eppley Precision Spectral Pyranometer (PSP), the direct normal irradiance from the Eppley Normal Incident Pyrheliometer (NIP), the pyrgeometer data from an Eppley pyrgeometer along with the case and dome temperatures, and a series of meteorological measurements for ambient temperature, wind speed, relative humidity, and atmospheric pressure. The absolute accuracy of the solar irradiance measurements is the larger of $15 \mathrm{~W} / \mathrm{m}^{2}$ or $2-3 \%{ }^{5}$.

At SRRL, the PSP and the pyrgeometer are mounted on ventilators. In addition, the Eppley pyrgeometer is on a tracker that shades the dome from direct sunlight. This provides more accurate pyrgeometer readings.

\section{CALCULATING THE IR RADIATIVE LOSSES}

Using the pyrgeometer and meteorological data at the site, the IR radiative losses are calculated using the full Younkin, Long radiative correction model ${ }^{1}$. This model uses the pyrgeometer measurements along with the case and dome temperatures to calculate the sky temperature. This information is combined with relative humidity measurements to calculate the IR radiative loss expected from a pyranometer. This model assumes that the IR responsivities of various Eppley PSP pyranometers are approximately the same. Also the broadband and the IR responsivities of a given PSP are proportional to one another. One part of the full correction procedure uses the measurements from the pyrgeometer detector. This part is called the detector only correction. This does not include other factors such as relative humidity that gives the full Younkin, Long methodology a broader range of IR radiative losses and reflect more of what is really seen by the first class thermopile pyranometers. These two methods will be referred to as the full correction and the detector only correction methods in this article. 
In the SRRL dataset, the IR radiative losses are estimated by correcting the PSP measurements in a method similar to the detector only method. NREL uses the Net-IR responsivity of the PSP pyranometer to correct for the IR radiative losses. The Net-IR responsivity is derived by calibrating the PSP with a blackbody to simulate the ambient and sky temperature ${ }^{2}$. The net downward IR flux is calculated by subtracting the pyrgeometer detector temperature measurements $\left(\sigma \mathrm{T}_{\mathrm{dt}}{ }^{4}\right)$ from the pyrgeometer-measured downward IR flux. This radiative flux is then divided by the broadband responsivity of the instrument and multiplied by the instrument's Net-IR responsivity. This SRRL method and the detector only method are similar to the SRRL method specifically designed for the pyranometer under study. This method will be referred to as the modified detector model.

\section{NIGHTTIME IR RADIATIVE LOSSES}

Nighttime is when the IR radiative losses from a pyranometer can be measured best. At night, there is no incident solar irradiance to affect the measurements. There are be small errors in measurement from the data logger and/or other external influences, such as rectification of radio waves, but these are small $\left(1 \mathrm{~W} / \mathrm{m}^{2}\right.$ or less $)$ in comparison to the IR radiative losses.

A series of comparisons of different IR Radiative Loss models with the PSP night values are made. In addition, a nighttime correlation using only meteorological variables developed for the Golden, Colorado data is studied. The nighttime correlation developed for the Eugene data is also compared with nighttime PSP measured values. The daytime comparisons will be made in the next section.

A sample of the nighttime irradiance values plotted in Fig. 1 shows the full correction and the detector only correction against the PSP nighttime readings. As expected, the full correction fits better than the detector only correction. The SRRL method, called the modified detector only model, is shown in Fig. 2. The mean value of the modified detector model is closer to the values obtained by the PSP measurements.

To see how well the PSP offset can be modeled, a nighttime correlation was created for the SRRL data. The correlation parameters for the coefficients found to be significant are given in Table 1. Also given are the standard deviations of the uncertainty in each parameter. The table includes the average value of the parameter and the typical value of the parameter. Adding all the typical values together yields the typical IR radiative value of $-10 \mathrm{~W} / \mathrm{m}^{2}$. The overall standard error for the nighttime correlation is $\pm 1.1 \mathrm{~W} / \mathrm{m}^{2}$.

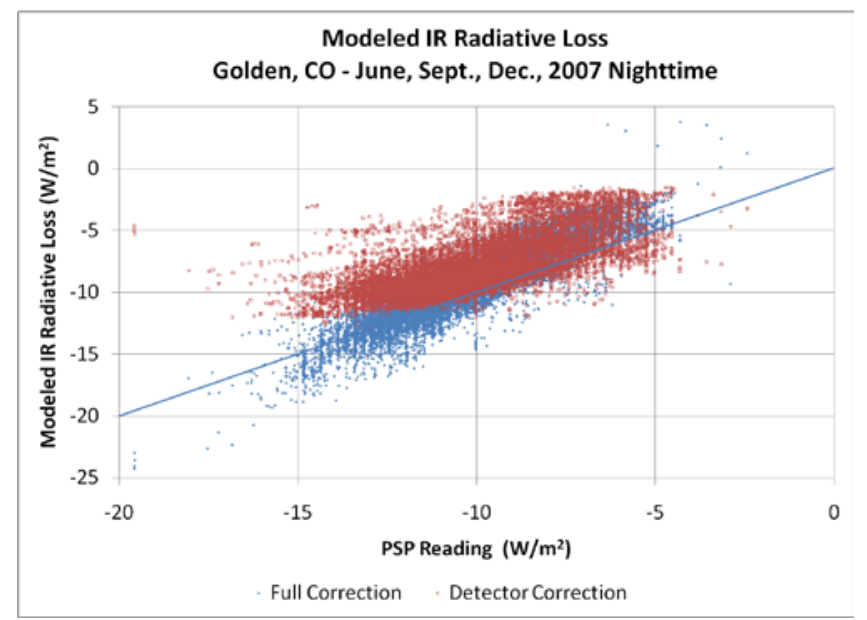

Fig. 1. Comparison of the full correction and detector only IR radiative loss models during the night. The full correction model significantly improves on the estimated IR radiative losses when they are greatest (between -10 and $-15 \mathrm{~W} / \mathrm{m}^{2}$ ).

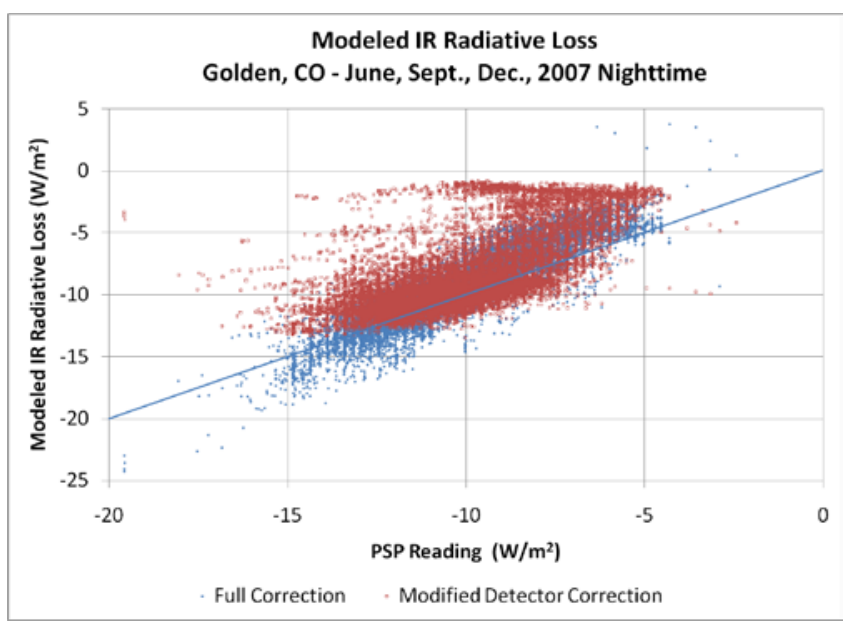

Fig. 2. Comparison between the full correction and the modificed detector correction for the IR radiative losses during the night. By measuring the pyranometer's IR responsivity, an improvement in the estimated IR radiative loss can be achieved. While the difference at higher IR radiative loss values is smaller, it still exists. In addition there is a shift of many points to low estimated IR radiative loss values. The reason for this shift should be investigated. 
Note that the correlation did not use data from periods when the data was missing or marked bad. Also, when the change of variable with time was derived, periods that did not have previous data values were not used in the correlation data set. Time periods very near sunrise and sunset were not used as some sky brightening might affect the measurements.

Table 1: Correlation parameters to the nighttime IR radiative loss fit

\begin{tabular}{|c|c|c|c|c|}
\hline Parameter & Coefficient & $\%$ Standard deviation & Average & Typical Value \\
\hline Intercept & -9.2650608 & $-7.89 \%$ & na & -9.3 \\
\hline Ambient Temperature & -0.0608274 & $-0.93 \%$ & $282 \mathrm{~K}$ & -17.2 \\
\hline Delta Temp. & -7.4522427 & $1.09 \%$ & 0 & 0 \\
\hline Relative Humidity & 0.0786042 & $1.46 \%$ & \multirow[t]{2}{*}{$50 \%$} & \multirow[t]{2}{*}{3.0} \\
\hline $\mathrm{RH}^{2}$ & -0.0003823 & $-2.57 \%$ & & \\
\hline Wind Speed & -0.6346762 & $-0.74 \%$ & \multirow[t]{2}{*}{$2.6 \mathrm{~m} / \mathrm{s}$} & \multirow[t]{2}{*}{-1.4} \\
\hline $\mathrm{WS}^{2}$ & 0.0334419 & $1.28 \%$ & & \\
\hline Delta WS & -0.1993351 & $3.58 \%$ & 0 & 0 \\
\hline Pressure & 0.0182993 & $5.14 \%$ & $815 \mathrm{hPa}$ & 14.9 \\
\hline
\end{tabular}

The values for Delta Temperature and Delta Wind Speed were determined by subtracting the current value from the value obtained from the previous minute. The changes in relative humidity and pressure did not turn out to be significant variables.

The Eugene correlation method used the hours from sunset as a parameter. This parameter was not used here because the number of hours from sunset changes from month to month and depends on location. Instead, the average value of five hours after sunset was used.

The comparison of the nighttime correlations from Eugene data and Golden data is shown in Fig. 3. The correlation parameters obtained from the Eugene data did not utilize the change in ambient temperature or the change in wind speed over time. The Golden nighttime correlation was developed from nighttime data in June, September, and December of 2007. March, 2007 data are utilized for comparison because the March data were not used in the correlation.

The nighttime Golden correlation obtained from June, September, and December shows a small bias when compared with the March data. Therefore the Golden correlation needs to be more thoroughly examined to determine the cause of this bias and to obtain an improved correlation model.

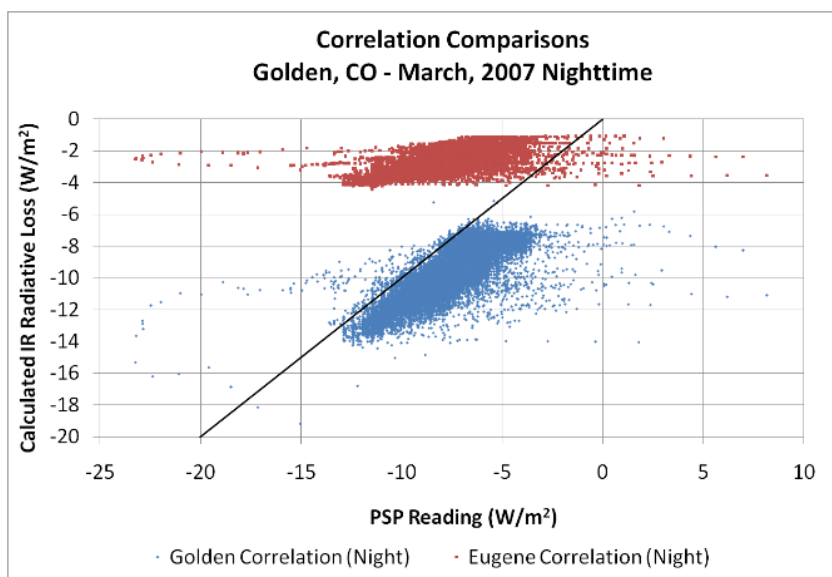

Fig. 3. Comparison of the Golden nighttime correlation model and the Eugene nighttime correlation model with the measured PSP nighttime readings. The Eugene night correlation model significantly underestimates the PSP IR radiative reading, never getting smaller than about -4 $\mathrm{W} / \mathrm{m}^{2}$.

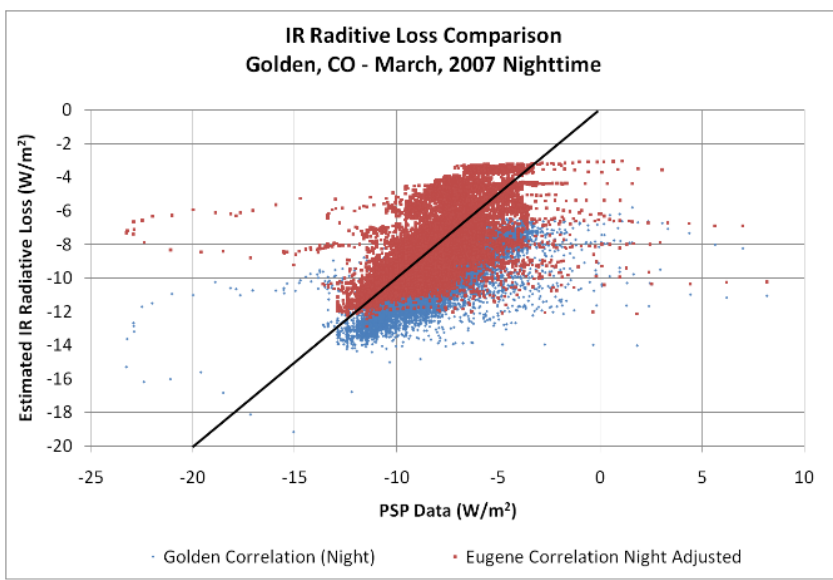

Fig. 4. Comparison of the adjusted Eugene nighttime correlation model and the Golden nighttime correlation model with the measured PSP nighttime readings. The Eugene nighttime correlation values were multiplied by 2.9 , the ratio of the average PSP nighttime measurements and the average Eugene nighttime correlation results. 


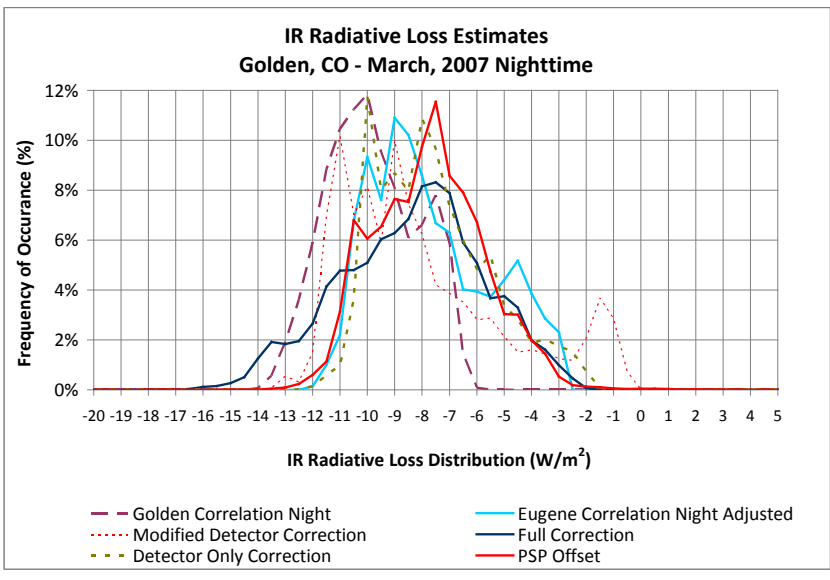

Fig. 5. Distribution of IR radiative loss values from the PSP measured nighttime values and the other models being studied. The plot represents over 20,000 one minute data points divided into $0.5 \mathrm{~W} / \mathrm{m}^{2}$ bins.
As expected, the Eugene correlation was not close to matching the observed IR radiative losses seen in Golden, Colorado. The sky temperature at the high altitude site in Golden has different characteristics than the sky temperature around the low altitude site in Eugene. This difference in IR radiative losses accounts for much of the change in responsivity of the pyranometers observed in Eugene as opposed to the responsivities measured in Golden.

The mean value of the Eugene correlation results is 2.9 times smaller than the mean of the observed IR radiative losses in Golden. The effect of multiplying the Eugene correlation values by 2.9 is shown in Fig. 4. After normalizing the model to the observed nighttime IR radiative losses, the modified modeled values provide a much closer match to the observed IR radiative losses.

Another way to look at the match between the PSP IR radiative losses and those predicted by the various models is to plot the frequency distribution of modeled IR radiative losses against the observed nighttime PSP values. The frequency distributions are given in Fig. 5. The full correction and the adjusted Eugene correlation give the best fits, for the March, 2007 data. The results should be compared with all the available data to see if the March data provides a typical comparison.

\section{DAYTIME IR RADIATIVE LOSSES}

The IR radiative losses during the day can be evaluated now that the nighttime IR radiative losses have been examined. Pyranometers also exhibit deviations from true cosine response, a measurable dependence on temperature, and possibly other minor systematic errors in addition to the IR radiative losses. The uncertainties associated with the measurement of incident radiation when combined with the systematic errors in the measurements make it very difficult to directly measure the IR radiative losses during daylight hours. Therefore, the full correction method that has been tested at a number of locations ${ }^{1}$ will be used as a segregate for the IR radiative losses during the daytime hours.

Table 2: Correlation parameters to the daytime IR radiative loss fit

\begin{tabular}{|c|c|c|c|c|}
\hline Parameter & Coefficient & \% Standard Deviation & Average & Typical Value \\
\hline Ambient Temperature & -0.151056 & $1.44 \%$ & $289 \mathrm{~K}$ & -43.81 \\
\hline Delta Temp. & -10.554729 & $1.61 \%$ & 0 & 0 \\
\hline Relative Humidity (\%) & 0.253814 & $-1.14 \%$ & \multirow[t]{2}{*}{$40 \%$} & 6.99 \\
\hline $\mathrm{RH}^{2}$ & -0.001978 & $1.32 \%$ & & 0 \\
\hline Wind Speed & -0.448232 & $1.55 \%$ & $2.6 \mathrm{~m} / \mathrm{s}$ & \multirow[t]{2}{*}{-2.30} \\
\hline Delta WS & -0.163556 & $11.59 \%$ & 0 & \\
\hline Pressure & 0.029178 & $-2.80 \%$ & $816 \mathrm{hPa}$ & 23.78 \\
\hline $\mathrm{k}_{\mathrm{b}}$ & -56.094918 & $1.64 \%$ & \multirow[t]{3}{*}{0.2} & \multirow[t]{3}{*}{-8.37} \\
\hline $\mathrm{k}_{\mathrm{b}}^{2}$ & 85.389791 & $-3.36 \%$ & & \\
\hline $\mathrm{k}_{\mathrm{b}}^{3}$ & -71.101465 & $3.95 \%$ & & \\
\hline Delta $\mathrm{k}_{\mathrm{b}}$ & -5.158391 & $6.80 \%$ & 0 & 0 \\
\hline $\mathrm{k}_{\mathrm{t}}$ & 23.031028 & $-3.08 \%$ & \multirow[t]{3}{*}{0.52} & \multirow[t]{3}{*}{6.50} \\
\hline $\mathrm{k}_{\mathrm{t}}^{2}$ & -39.262094 & $4.80 \%$ & & \\
\hline $\mathrm{k}_{\mathrm{t}}^{3}$ & 34.940895 & $-3.67 \%$ & & \\
\hline $\operatorname{Cos}(\mathrm{Z})$ & -4.743173 & $5.42 \%$ & \multirow[t]{2}{*}{0.5} & \multirow[t]{2}{*}{2.38} \\
\hline $\operatorname{Cos}^{2}(Z)$ & 19.013970 & $-1.34 \%$ & & \\
\hline
\end{tabular}




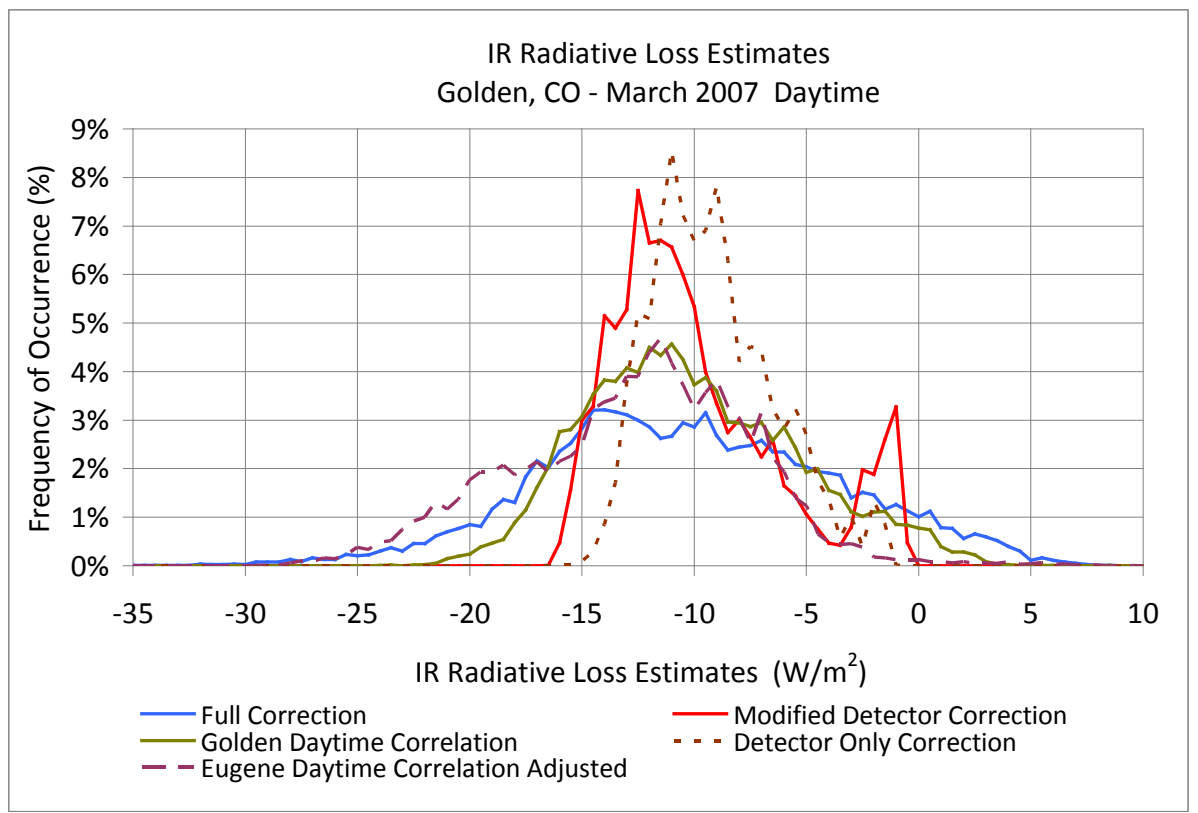

Fig. 6. Distribution of IR radiative loss values during the day from the models under study. The data are from SRRL in March, 2007. The plot represents over 20,000 one minute data points divided into $0.5 \mathrm{~W} / \mathrm{m} 2$ bins.

As with the nighttime IR radiative loss examination, the months of June, September, and December 2007 were used in deriving a correlation for the Golden, Colorado data against the full correction IR radiative loss estimates. Table 2 gives the statistically significant correlation parameters and their coefficients along with the standard deviations for the model for estimating the IR radiative loss. Note that both the global and beam values were normalized by dividing by their relative extraterrestrial values, giving $k_{t}$ and $k_{b}$ respectively. The standard error for the correlation is approximately $3.4 \mathrm{~W} / \mathrm{m}^{2}$, which is a about a $1 / 3$ of the estimated IR radiative loss values.

The adjustment to the Eugene daytime correlation model is to multiply the calculated values by the 2.9 factor

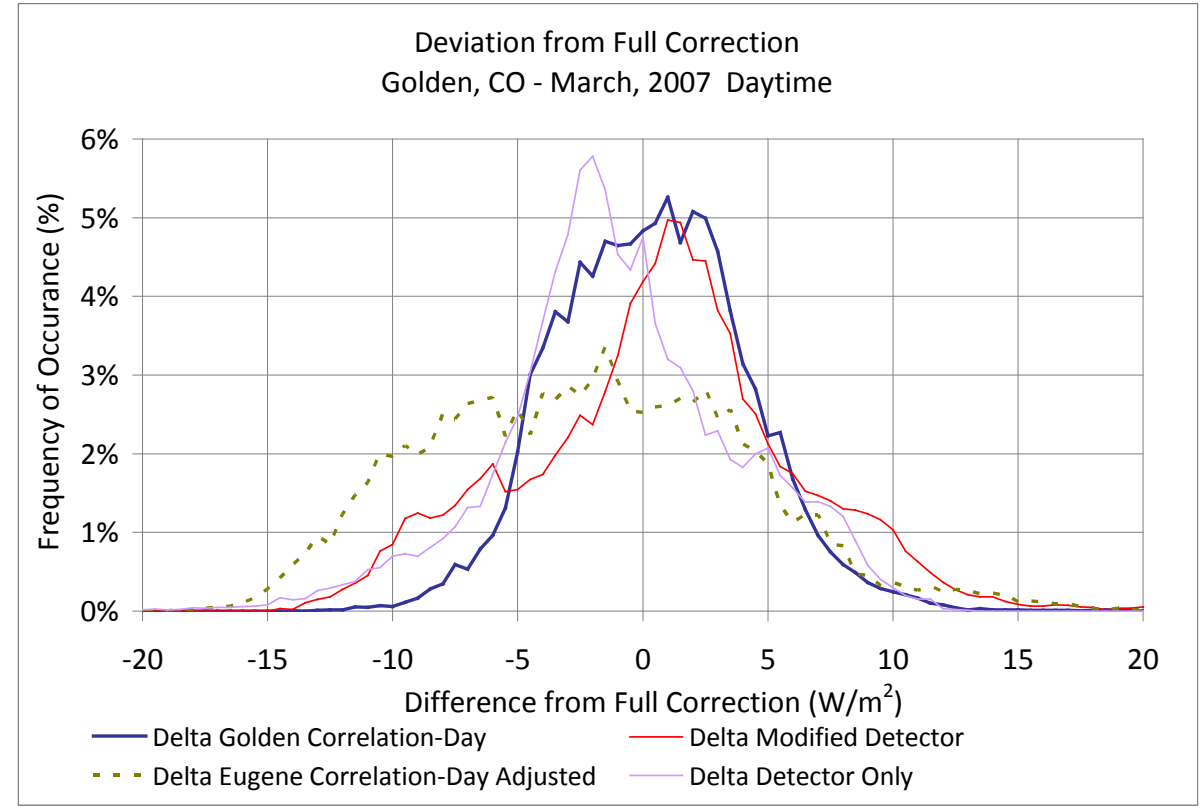

Fig. 7. Distribution of the difference between the full correction model IR radiative loss values during the day from those of other models under study. Data from SRRL in March, 2007. Plot represents over 20,000 one minute data points divided into 0.5 $\mathrm{W} / \mathrm{m}^{2}$ bins. 
determined from the ratio of measured nighttime PSP values and the estimated IR radiative losses using the Eugene nighttime correlation model. The comparison with the adjusted Eugene correlation model will help test whether a nonpyrgeometer based correlation developed in one area is scalable to different regions. The difference between the full correction model and the detector only, the modified detector model, the Golden daytime correlation, and the adjusted Eugene daytime correlation are shown in Fig. 6. March, 2007 data are used for the evaluation in Fig. 6 because March data was not used to develop the Golden correlation model.

The detector based models give approximately the right average IR radiative loss value, but do not show the distribution of values exhibited by the full correction. The modified detector model exhibits a peak at low IR radiative loss values, and it is uncertain why this occurs. Both the modified Eugene and the Golden calibrations seem to better match the distribution of the full correction values. However, while the distributions are similar they still deviate from the full correction.

Another way to compare the IR radiative loss predictions is to plot the distribution of the difference between the full correction model and the other IR radiative loss models. This comparison is shown in Fig. 7. The difference from the Golden correlation model appears to have a normal distribution. While March data were not used in the development of the Golden correlation model, it is expected that the characteristics of the IR radiative losses in March should behave similarly to those in other months for a given location. The distribution for the Eugene correlation is fairly flat and skewed to the higher average difference between the full correction model and the Eugene model.

The detector model and parts of the modified detector model are incorporated in the full correction model and the predicted IR radiative loss values should be fairly similar as seen in Fig. 7. The modified detector model moves the peak of the difference closer to the full correction, but studies from more sites are needed before any firm conclusions can be drawn.

\section{DISCUSSION AND CONCLUSIONS}

A good model of the IR radiative losses from first class thermopile pyranometers such as the Eppley PSP would be useful in obtaining more accurate measurements of the total irradiance. This is especially true for diffuse measurements where the IR radiative losses can be between 10 and $20 \%$ of the clear day values. The use of pyrgeometers to model IR radiative losses has been demonstrated already ${ }^{1}$. However there is a considerable amount of high quality pyranometer data from sites that do not have pyrgeometer data to correct for the IR radiative losses. Therefore a model that corrects for IR radiative losses using pyranometer and meteorological data could prove useful. In early work ${ }^{3,4}$ modeling the IR radiative losses using pyranometer and meteorological data were examined for one site (Eugene, Oregon). It is was found that a correlation model based on meteorological and short wavelength solar measurements could simulate the IR radiative losses obtained from pyrgeometer measurements. However it was evident that the model was site specific and that a method was needed to transform the model so that it could work at sites with different sky temperature characteristics. In particular, significant differences between the nighttime IR radiative losses in Eugene and Golden, Colorado, given similar meteorological conditions, were noted.

In this article it was found that using the ratio of nighttime IR radiative losses, the meteorologically based IR radiative correlation models developed in Eugene could be scaled to simulate the IR radiative losses obtained by the comprehensive full correction IR radiative loss model. While the fit for the Eugene model was not perfect, it did show in principle that a well developed IR radiative loss model not requiring pyrgeometer data could be developed.

In other words, the bulk of the difference between the IR radiative losses observed at different sites can be accounted for by the ratio of the nighttime IR radiative losses. This result holds for Eppley PSP pyranometers and assumes that the IR radiative losses for different PSPs are similar. The difference between the detector only and the modified detector model shows that there probably are some differences between instruments, but these differences are assumed to be small, and taking the nighttime IR radiative loss ratio will probably include some of this difference.

The fact that the full correction model works for many locations shows that the pyrgeometer characterization of the sky temperature and the use of meteorological measurements that enhance the model can fairly accurately account for 
the IR radiative losses. This is clearly illustrated in Fig. 5, which shows the match between the IR radiative losses at night between the PSP measurements and the full correction model. This model has been tested using different PSP pyranometers and gives good results without specifying the exact IR profile of each pyranometer. This is probably because the IR profiles of the pyranometers are similar.

While the Eugene or Golden correlation models of IR radiative losses are useful prototypes for estimating IR radiative losses without pyrgeometer data, a full comprehensive model will require evaluation over a number of years and at a variety of sites.

\section{ACKNOWLEDGEMENTS}

The UO SRML Solar Monitoring Network and data analysis is sponsored by the Bonneville Power Administration, Eugene Water and Electric Board, the Energy Trust of Oregon, the National Renewable Energy Laboratory, Emerald People's Utility District and the Salmon River Electric Cooperative. Dr. Long acknowledges the support of the Climate Change Research Division of the U.S. Department of Energy as part of the Atmospheric Radiation Measurement (ARM) Program.

\section{REFERENCES}

[1] Younkin, K. and C. N. Long, "Improved Correction of IR Loss in Diffuse Shortwave Measurements: An ARM Value Added Product," Atmospheric Radiation Measurement Program Technical Report, ARM TR-009, 50 pp., (2004) Available via http://www.arm.gov/publications/techreports.stm. (2004)

[2] Reda, I., Hickey, J., Long, C., Myers, D., Stoffel, T., Wilcox, S., Michalsky, J.J., Dutton, E.G., and Nelson, D., "Using a blackbody to calculate net infrared responsivity of shortwave solar pyranometers to correct for their thermal offset error during outdoor calibration using the component sum method," J. Atmospheric Oceanic Tech., vol. 22, pp. 1531-1540, October 2005.

[3] Vignola, F., Long, C., Reda, I., "Evaluation of Methods to Correct for IR Loss in Eppley PSP Diffuse Measurements", proceeding SPIE conference, San Diego (2007)

[4] Vignola, F., Long, C., Reda, I., "Modeling IR Radiative Loss from Eppley PSP Pyranometers", proceeding SPIE conference, San Diego (2008)

[5] NREL solar radiation data: http://www.nrel.gov/midc/srrl_bms/ 


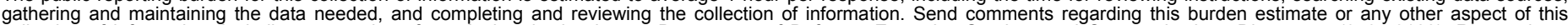

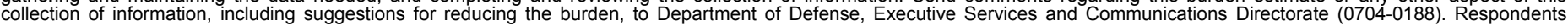

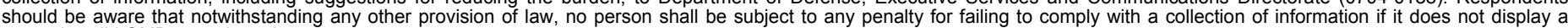

should be aware that notwithstanding

PLEASE DO NOT RETURN YOUR FORM TO THE ABOVE ORGANIZATION.

\begin{tabular}{|c|c|c|}
\hline $\begin{array}{l}\text { 1. REPORT DATE (DD-MM-YYYY) } \\
\text { August } 2009\end{array}$ & $\begin{array}{ll}\text { 2. } & \text { REPORT TYPE } \\
& \text { Conference Paper }\end{array}$ & 3. DATES COVERED (From - To, \\
\hline
\end{tabular}

4.
TITLE AND SUBTITLE
Testing a Model of IR Radiative Losses

DE-AC36-08-GO28308

5b. GRANT NUMBER

5c. PROGRAM ELEMENT NUMBER

6. AUTHOR(S)

F. Vignola, C.N. Long, and I. Reda

5d. PROJECT NUMBER

NREL/CP-3B0-46411

5e. TASK NUMBER

3B10.1000

5f. WORK UNIT NUMBER
7. PERFORMING ORGANIZATION NAME(S) AND ADDRESS(ES)

National Renewable Energy Laboratory

1617 Cole Blvd.

Golden, CO 80401-3393

9. SPONSORING/MONITORING AGENCY NAME(S) AND ADDRESS(ES)

\section{PERFORMING ORGANIZATION REPORT NUMBER}

NREL/CP-3B0-46411
10. SPONSOR/MONITOR'S ACRONYM(S) NREL

11. SPONSORING/MONITORING AGENCY REPORT NUMBER

12. DISTRIBUTION AVAILABILITY STATEMENT

National Technical Information Service

U.S. Department of Commerce

5285 Port Royal Road

Springfield, VA 22161

13. SUPPLEMENTARY NOTES

14. ABSTRACT (Maximum 200 Words)

Thermopile pyranometers exhibit IR radiative losses that affect global and diffuse shortwave measurements made with first class thermopile based instruments. Pyrgeometers can be used to measure the sky temperature and are used to calculate the pyranometer's IR radiative losses. Few solar monitoring sites are equipped with pyrgeometers necessary to account for the IR radiative losses associated with the pyranometers. High quality data from the Solar Radiation Research Laboratory (SRRL) at the National Renewable Energy Laboratory are used to test and further develop a model for the IR radiative losses without the use of pyrgeometer data. The various methods for obtaining $I R$ radiative loss values are compared and contrasted using the SRRL data. A simple scaling method is proposed and tested to adjust the non-pyrgeometer based correlation models to sites with different sky temperature characteristics.

15. SUBJECT TERMS

Pyranometer; Pyrgeometer; irradiance; IR; modeling; global; PSP

\begin{tabular}{|c|c|c|c|c|}
\hline \multicolumn{3}{|c|}{ 16. SECURITY CLASSIFICATION OF: } & \multirow{2}{*}{$\begin{array}{l}\text { 17. LIMITATION } \\
\text { OF ABSTRACT } \\
\text { UL }\end{array}$} & \multirow{2}{*}{$\begin{array}{l}\text { 18. NUMBER } \\
\text { OF PAGES }\end{array}$} \\
\hline $\begin{array}{l}\text { a. REPORT } \\
\text { Unclassified }\end{array}$ & $\begin{array}{l}\text { b. ABSTRACT } \\
\text { Unclassified }\end{array}$ & $\begin{array}{l}\text { c. THIS PAGE } \\
\text { Unclassified }\end{array}$ & & \\
\hline
\end{tabular}

19a. NAME OF RESPONSIBLE PERSON

19b. TELEPHONE NUMBER (Include area code) 